\title{
NEW SPECIES AND OCCURRENCES OF UROPODINA MITES (MESOSTIGMATA) FROM BRAZILIAN CAVES
}

\author{
Pedro H.S. Conceição ${ }^{1}$ and Almir R. Pepato ${ }^{1,2^{*}}$
}

\author{
${ }^{1}$ Departamento de Zoologia, Instituto de Ciências Biológicas, Universidade Federal de Minas \\ Gerais, Belo Horizonte, Minas Gerais, Brazil \\ ${ }^{2} \mathrm{X}-\mathrm{BIO}$ Institute, Tyumen State University, Tyumen, Russia \\ *corresponding author; e-mail: apepato@gmail.com
}

\begin{abstract}
A new species belonging to the genus Uroseius Berlese, 1888 (Trachytidae, Mesostigmata) is described based on the morphological characters of three females and one male collected from caves in Minas Gerais State, Brazil. The new species differs from other Neotropical species in having two shapes of idiosomatic ventral and dorsal setae, a character shared with Palearctic species. New occurrences of Oplitis apicalis Lopes, Oliveira, Delabie and Klompen, 2015 are also reported.
\end{abstract}

KEY WORDS: Uroseius, Oplitis, Trachytidae, Neotropic, Cave dwelling mites.

DOI: 10.21684/0132-8077-2021-29-2-247-256

\section{INTRODUCTION}

Uropodina is a common element of litter and soil fauna in the tropics. They occur as both free dwellers and as phoretic deutonymphs, mainly associated with other arthropods (Lindquist et al. 2009). They are commonly found in caves (Bernardi et al. 2009). The systematics of the widespread genus Uroseius Berlese, 1888 is complicated by the apparent mixture of plesiomorphic and apomorphic characters. In particular, general fragmentation and reduction of idiosomatal sclerotization are characteristic of some of the so-called "lower" Uropodina (Ainscough 1979).

The above characteristics provided the basis for Hirschmann and Zirngiebl-Nicol (1961) to merge Uroseius with the genera Apionoseius Berlese, 1904, Dithinozercon Berlese, 1916 and Polyaspinus Berlese, 1916. Additionally, Hirschmann and ZirngieblNicol (1964) synonymized Iphidinychus Berlese, 1913, Caminella Krantz and Ainscough, 1960 and Pholeogynium Johnston, 1961. All of the above were included in the subgenus $U$. (Apionoseius) (Berlese, 1904), while the subgenus $U$. (Uroseius) retained the species originally described for the genus and Pholeogynium sorrentinus (Lombardini, 1952), synonymized to Uroseius (U.) hunzikeri Schweizer, 1922 (Halliday 2015).

Ainscough (1979), however, moved all species belonging to $U$. (Apionoseius) to the superfamily Polyaspidoidea. Currently, Uroseius sensu stricto comprises 19 species: three are known from females, ten from deutonymphs only, five from females and deutonymphs, and a single species, $U$. sorrentinus, had its females, males and deutonymphs described (Moraza and Pérez-Martínez 2019; Moraza 2019).
No formal occurrences of Uroseius s.s. were found in Brazil, although an unknown species associated with domestic flies in chicken litter was recorded (Rodrigueiro and Prado 2004).

The genus Oplitis was proposed by Berlese (1884) and revised more recently by Hirschmann (1991). It is one of the most diverse genera of Uropodina with about 150 described species (Babaeian et al. 2016). Different authors considered it a member of the families Uropodidae, Trachyuropodidae and Oplitidae. Here, we follow Lopes et al. (2015) in considering the species group (Artengruppen) established by Hirschmann, as a genus; and the genus Oplitis as the family Oplitidae, in which the authors described the species Oplitis apicalis Lopes, Oliveira, Delabie and Klompen, 2015.

The above genus is usually associated with ants, termites, or their nests: its adult instars are mostly found on ants (Lopes et al. 2015). However, some species have been collected from soil and litter. The genus Oplitis has a worldwide distribution.

In this article, we describe a new species of Uroseius and record new occurrences of Oplitis apicalis. All the mites were obtained from caves located in Minas Gerais State, Brazil—a biodiverse and threatened environment.

\section{MATERIALS AND METHODS}

The mites were hand-captured in caves located in Minas Gerais State, southeastern Brazil. They were stored in $70 \%$ alcohol, slide mounted in Hoyer's medium (Walter and Krantz 2009) or in glycerin jelly (Green and Macquitty 1987) and deposited in the Acarological Collection of the 
Centro de Coleções Taxonômicas da Universidade Federal de Minas Gerais (UFMG AC).

The slide mounted mites were studied using a Leica DM2500 compound microscope equipped with a camera lucida. Original drawings are pencil line drawings. Final artwork was prepared using Adobe Illustrator CS5. Measurements and pictures were taken using the Leica DM 750 optical microscope with an attached ICC50W digital camera, which was calibrated using a graduated slide. All measurements are given in micrometers $(\mu \mathrm{m})$, indicating ranges, when more than one individual per stage was available. Structures were measured according to Moraza (2019). In particular, dorsal shield lengths are midlines from the posterior margin of the vertex to the caudal margin. Other idiosomatic shields are midlines from the anterior margin to the posterior edge of each structure. Leg lengths are measured from the bases of the coxae to the apex of the tarsus, excluding the pretarsus.

The terminology and abbreviations employed throughout the description follow Moraza (2019) when redescribing $U$. sorrentinus (Lombardini, 1952) and Moraza and Pérez-Martínez (2019) when describing U. foetidus Moraza et Pérez-Martínez, 2019, as well as references cited therein. The classification of Uropodina into superfamilies follows Beaulieu et al. (2011).

Geographic coordinates were acquired from GPS upon collection.

\section{SYSTEMATICS}

\section{Superfamily Uropodoidea Kramer, 1881 \\ Family Trachytidae Tragärdh, 1938 \\ Genus Uroseius Berlese, 1888 \\ Uroseius Berlese, 1888: 3.}

Type species Uropoda acuminata Koch, 1847: 260 , by monotypy.

Diagnosis. The concept of Uroseius used here is based on that of Moraza and Pérez-Martínez (2019) and Moraza (2019)

\section{Uroseius subterraneus sp.n.}

Figs. 1-5

Diagnosis. Uroseius with 2 shapes of dorsal and ventral idiosomal setae: 1) smooth and short needle-like, 2) long, stout and barbed club-shaped. 2 pairs of stout and barbed club-shaped setae on dorsal shield (J3-J4) and both setae morphologies on laterodorsal idiosoma. Marginal row of idiosomal setae needle-like. Caudal idiosomal protuberance absent. Setae JV1-JV2, ZV1-ZV2 smooth needle-like, 32-46 (37) long. Hypostomal setae $\mathrm{h} 4>\mathrm{h} 2$. Males with genital valves nude.

Description of adult female $(\mathrm{n}=3)$. Idiosomatic dorsum. Idiosoma rounded with prominent vertex, 952-1,020 (974) long, 738-820 (779) wide, with lateral projections and not covered by dorsal shield (Fig. 1C). Dorsal shield 850-920 (890) long, 503-524 (512) wide, weakly ornamented, covering the central region of idiosoma with irregular margin and bearing approximately 29-31 pairs of setae (j3-j6, z2-z6, s1-s6, J1-J4, Z1-Z3, S1-S2 and 12-17 supplementary " $\mathrm{x}$ " setae), J3-J4 thicker, longer barbed club-shaped setae 57-65 (60) (Figs. $1 \mathrm{C}, 4 \mathrm{~A}, \mathrm{~B})$, other setae smooth and needle-like 20-43 (32) long. Each seta on dorsal shield with 1 or 2 gland pores at base; marginal shield absent, lateral soft cuticle bearing approximately 29-30 pairs of setae, loosely arranged in 2 rows: marginal row with 10 pairs of supplementary setae $r x$ and $R x$ (two anterior needle-like and remaining 8 long barbed club-shaped); dorsal row comprising pairs of $r 1-r 6, R 1-R 6, J 5, S 3-S 5, Z 4-Z 5$, and supplementary pair of setae $x ; r 1-r 5, x, S 3-S 5$ and $Z 4$ smooth and short while remaining setae barbed club-shaped. Concerning setae morphology, lateral soft cuticle bears 13-14 pairs of smooth needle-like setae, and 15-17 pairs of long, barbed club setae. All dorsal setae on soft cuticle on rounded platelets bearing 2 or 3 glandular pores. 9 pairs of lyrifissures discernible: 2 on dorsal shield (idm1, idm3); 7 on membranous cuticle, 2 podonotal (idx in Fig. 1C) and 5 opisthonotal (id11-id15). Additionally, setae on marginal cuticle may be tentatively grouped in a marginal row that bends ventrally, ending anteriorly to lyrifissure ivp and JV5 with 10-13 pairs of smooth needle-like setae, 35-64 (46) long.

Idiosomatic venter (Fig. 1A, B). Sternal shield with very small punctuations (visible in $100 \times$ magnification), anterior margin truncate. Exopodal II-IV faintly paneled. Genital shield pear-like in shape, 200-233 (213) long, 116-142 (130) wide, nude, with punctate cuticle, anterior border varying from bifid (Fig. 2D) to almost truncate and crenulate (Fig. 1A). All sternal setae smooth and needle-like, similar in length 22-34 (27), each associated to a pore (gst1gst3); sternal setae $s t 1-s t 5$ borne on sclerotized cuticle around genital shield. 1 pair of lyrifissures discernible posterior to $s t 1$ (iv1) and another posterior to genital opening (iv5). Conspicuous pair of cuticular organs near endopodal II-III with two pores on a pair of rounded platelets (gst1, CO) (Figs. 1B, 4D). Parapodal, exopodal, peritrematal and metapodal elements with pigmented flexible cuticle faintly 


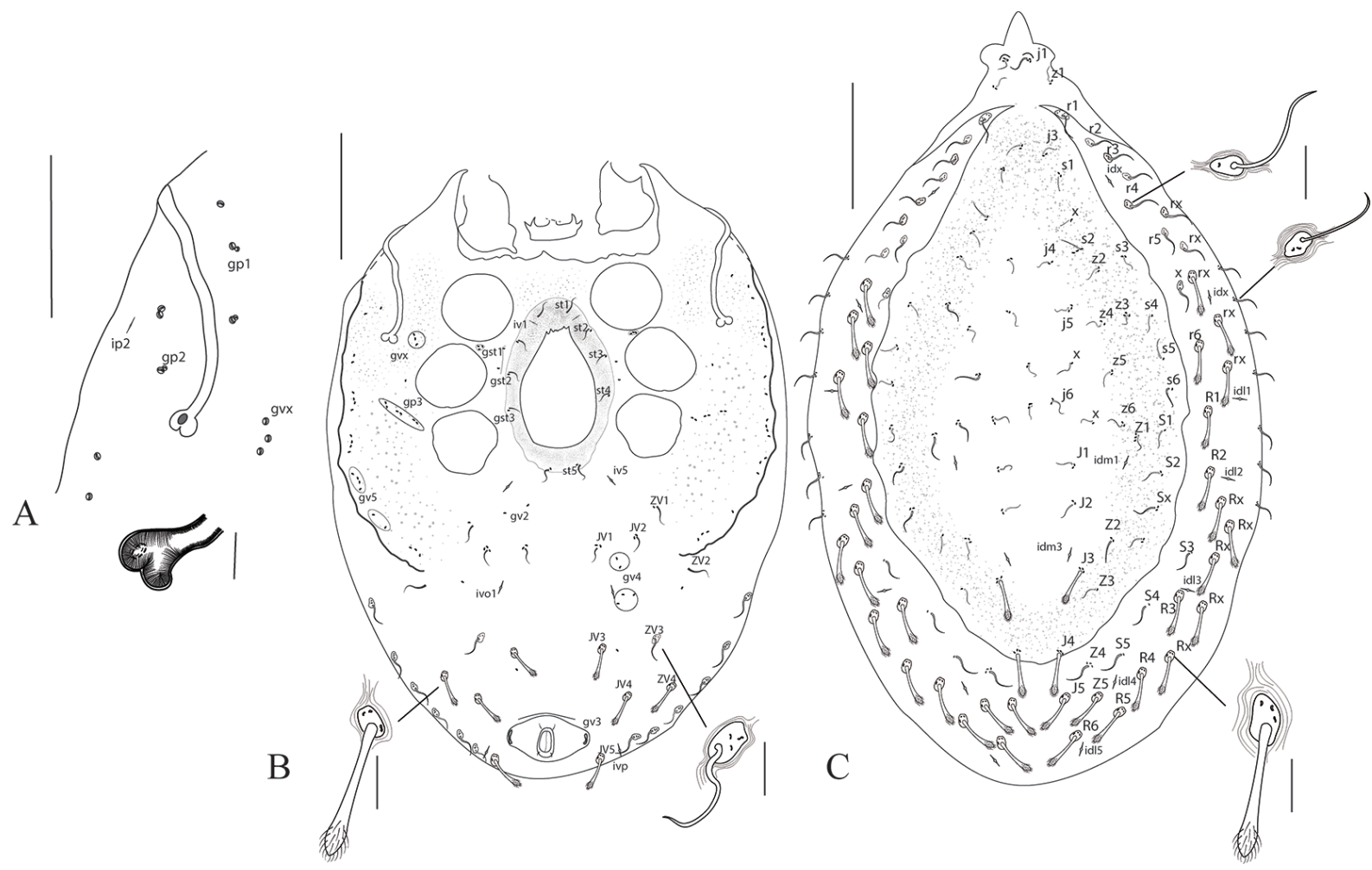

Fig. 1. Uroseius subterraneus sp.n., female. A - detail of peritremal area and stigma; B - idiosoma ventral view; Cidiosoma dorsal view. Setae and pores named according to Moraza (2019). Scale bars: A=100; B, C=200; setae and stigma in details $=25$.

paneled. Peritreme from posterior border of coxae I to anterior margin of coxae III, slightly bent in anterior region, with a short prestigmatal paraxial projection (Fig. 1A). 1 discernible lyrifissure lateral to peritremes (ip2) (Fig. 1A).

Opisthogastric region. Ventral shield bearing four pairs of smooth and needle-like setae (JVI$J V 2, Z V 1-Z V 2) 32-46$ (37) and four pairs of barbed club-shaped setae (JV3-JV5, ZV4) 45-54 (49) associated with gland pores. 2 pairs of lyrifissures discernible, ivol and ivp (Fig. 1B).

Anal shield 72-89 (80) long, 120-128 (125) wide, capturing a large pair of glands $g v 3$ at both sides. Anal opening 33-40 (35) long; 2 pairs of thin, short and smooth adanal setae, anterior pair $12-13$, posterior pair $14-17$, approximately.

Gnathosoma (Fig. 2A). Gnathotectum with one medial tapering prong bearing lateral spines, with 2 basal serrate projections laterally and a serrate crest (Fig. 2B). Salivary stylets (ss) well developed, 69100 (82) long. Internal mala feather-like, shorter than corniculi, with short fimbriae. Hypostomal setae complete only in Paratype (UFMG AC 210144), all smooth, setiform: $h 1(60)>h 3(59)>$ $h 4(18)>h 2$ (12). Corniculi horn-like, stout. Deutosternum gutter not well defined. Tritosternum bases 85-107 (95) wide, 22-35 (28) long, with smooth surface and lateral pointed projections; base of laciniae 49 long with 5 barbed branches (Fig. 2E).

Cheliceral measurements were available only for the individual UFMG AC 173943. Chelicerae (Fig. 2C) 436 long, without a distinct "nodus", fixed digit 63, movable digit 46. Fixed digit with several small teeth, movable digit with a single tooth. Fixed digit with conspicuous processes at dorsal surface of distal region bearing globular sensilla and 1 pilose lamella attached to ventral region (Fig. 2C); pilus dentilis absent; margin of arthrodial envelope smooth.

Palps leg-like 152-188 (170). Palptrochanter with three short spines at anterior lateral margin (pp) (Fig. 2A). Trochanteral setae $v 2$ long, all setae smooth with no barbs; all genual setae thin, setiform. Setal formula: 2-4-5-12-14. Palpal apotele (ap) bifurcate.

Legs (Fig. 3). Coxae I-IV with distinct glandular fields (Figs. 3A-D, 4C). Length of leg I 502-578 (544), leg II-521-610 (569), leg III520-588 (558), leg IV-596-677 (632). From femur to tibia, most dorsal and medial setae blunt spine-like (Fig. 3A-D), other setae slender. Leg chaetotaxy I-IV: coxae: $2-2-2-1$; trochanters: 

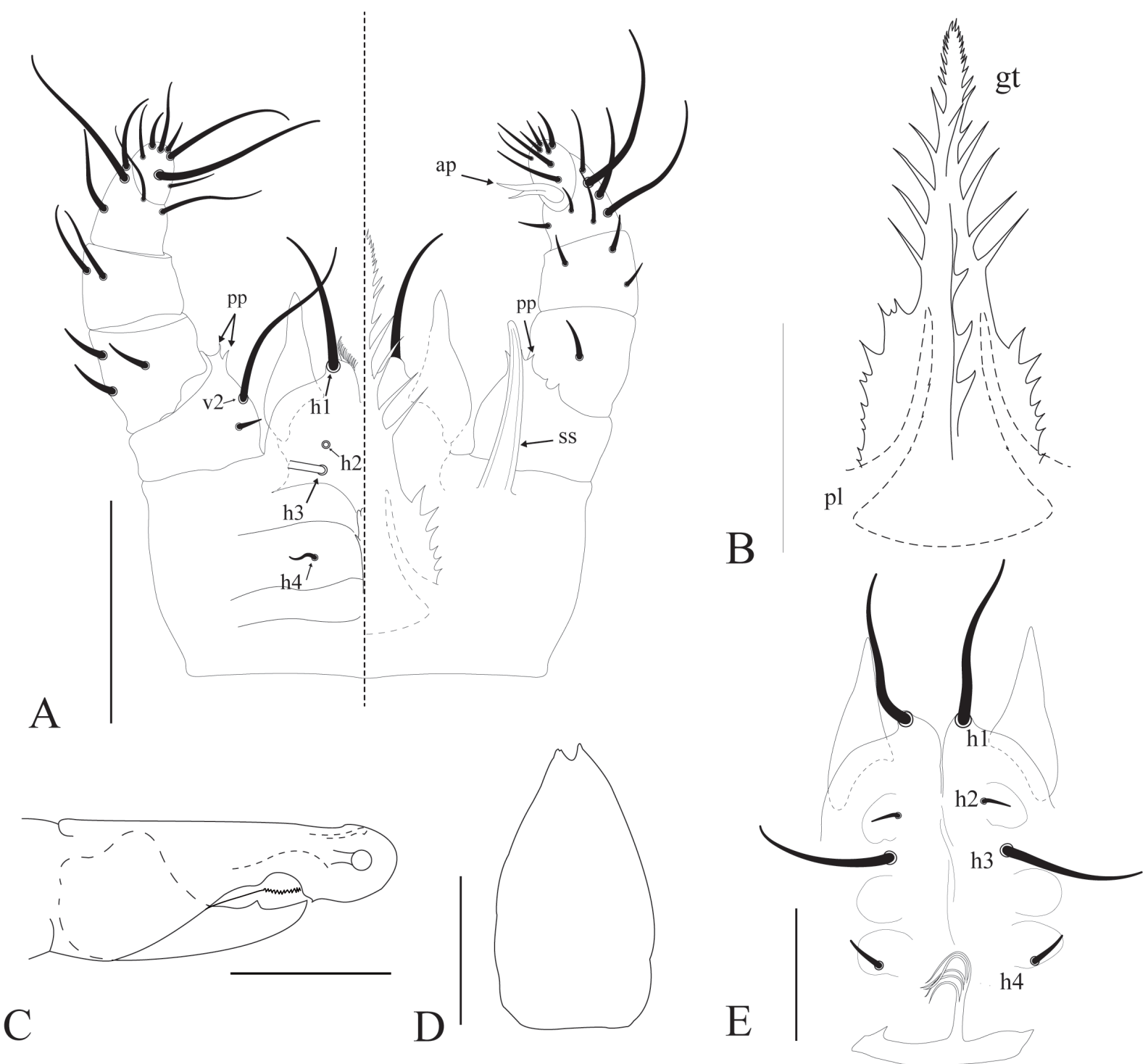

$\mathrm{C}$
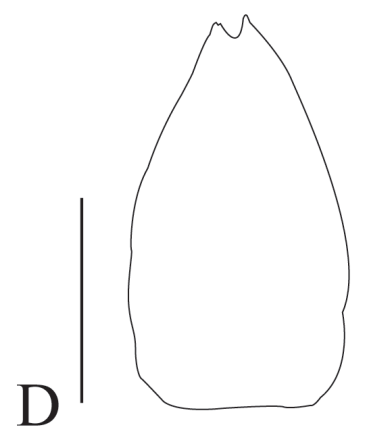

Fig. 2. Uroseius subterraneus sp.n. female. A — gnathosoma; B — gnatothectum and paralabrum; C-chelicera; Dgenital plate of individual UFMG AC 173943; E-subcapitulum and tritosternum of individual UFMG AC 210144. ap=bifurcate apotele; gt=gnatothectum; h1-4—hypostomal setae; pl—paralabrum; pp — prongs; ss—salivar stylet; v2-ventral setae 2. Scale bars: A, D-E=100; $B=50 ; C=25$.

4-4-4-4; femora: 2 2/1 2/1 1, 2 2/1 2/1 1, 1 2/1 1/0 1, 1 2/1 1/0 1; genu: 1 2/1 2/1 1, 1 2/1 2/1 1, $12 / 1$ 2/1 0, $12 / 12 / 00$; tibiae: all $11 / 12 / 11$; tarsi II-IV: all 3 3/2 1/1 3/2 3. Leg I pretarsus absent, tarsi I 140-160 (152) long, about 2.4 times longer than tibia (55-68 long). Pretarsi II-IV with distinct claws and pointed pulvillus. Tarsi II-IV with distal tarsal setae blunt tipped spine-like, similar in length, with al-1, $a v-1, p l-1$ and $p v-1$ stout, and with setae $a d-1, p d-1$ filiform 63-105 long; pretarsi 32-40 (34) long from bases of tarsi to bases of claws; dorso-apical gland absent.

Male (N=1). Length 1,065, width 790 .

Dorsum (Fig. 5A). Idiosomal shape similar to that of female. Vertex damaged in the individual available, but bearing pairs of $j 1$ and $z 1$. Dorsal shield broader than that of female, 908 long, 543 wide at widest level. It captures setae $S 3-S 4$ and $Z 4$, leaving a single pair of smooth setae (S5) out. Shield with 31 pairs of setae $(j 3-j 6, z 2-z 6, s 1-s 6$, $J 1-J 4, Z 1-Z 4, S 1-S 4$ and 10 supplementary setae), of which 2 pairs (J3-J4) long, stout, barbed clubshaped setae (74) similar to those observed in females. 2 pairs of lyrifissures discernible on plate (idm 1, idm3).

Soft cuticle surrounding dorsal shield with approximately 27 pairs of setae, loosely arranged in 2 rows with the same smooth needle-like setae and stout, barbed club-shaped setae morphologies (9 and 18 pairs, respectively) observed on dorsal 

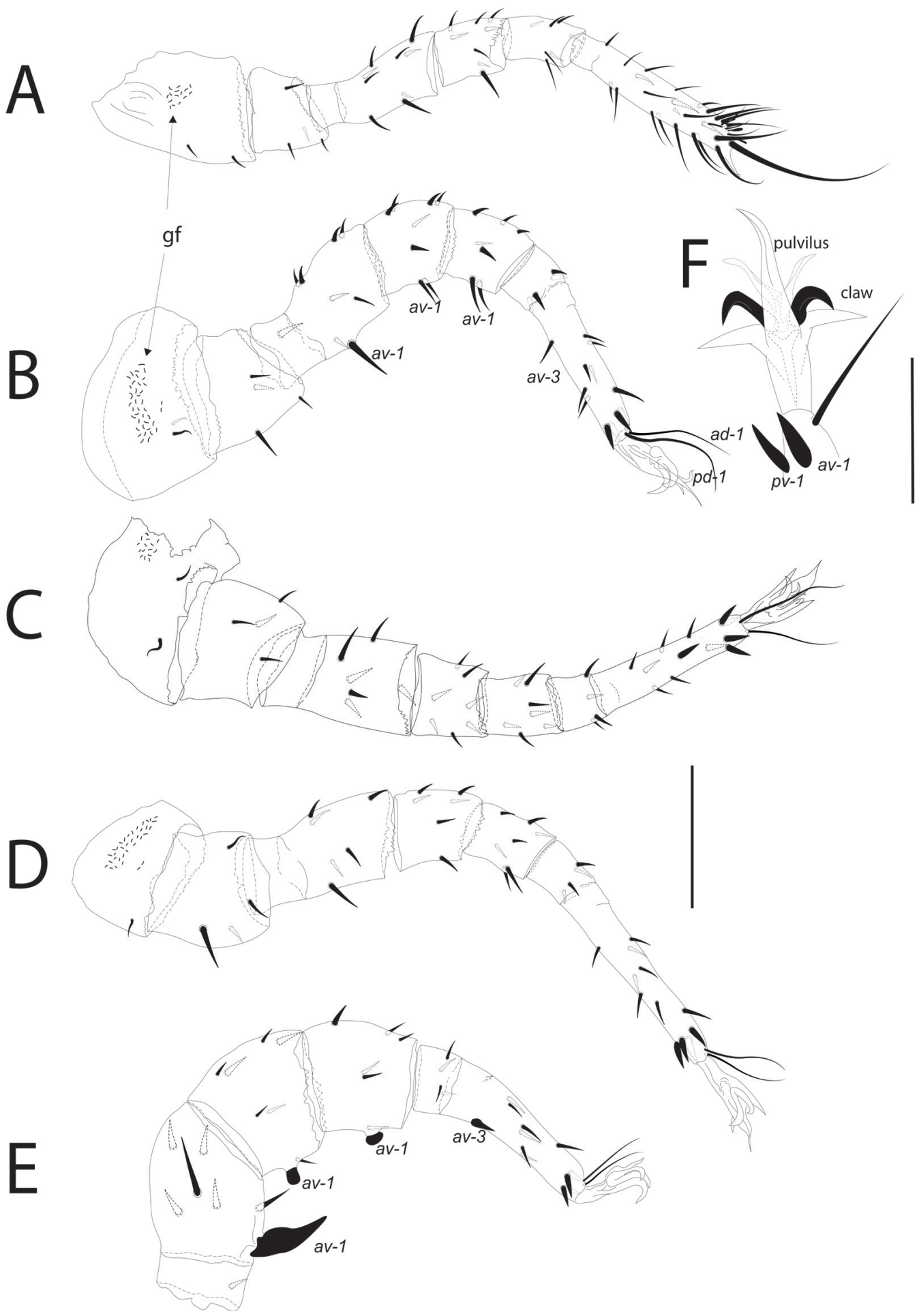

Fig. 3. Uroseius subterraneus sp.n. female. A-leg I; B-leg II; C—leg III; D—leg IV; male, E—detail of ambulacrum of leg II. F-leg II. gf - glandular fields. Scale bars: A-E=100; F=50. Setae named according to Moraza (2019).

shield, but each one placed on small platelets in the following way. 1 row with marginal supplementary setae ( $r x$ and $R x$ ) (anteriormost needle-like and remaining setae stout, barbed club-shaped); 1 dorsal row comprising pairs of $r 1-r 6, R 1-R 6, J 5, S 5$, $Z 5$ and 1 supplementary pair of setae $x$, where $r 1-r 5, x$ and $S 5$ smooth and short, while remaining pairs of setae stout, barbed club-shaped. 7 pairs of lyrifissures on membranous cuticle, 2 podonotal (idx) (Fig. 1C) and 5 opisthonotal (id11-idl5).

Additionally, setae on marginal cuticle may be tentatively grouped in 1 marginal row that bends ventrally, ending anteriorly to JV5 with 11 pairs of smooth needle-like setae, 38-66 (47) long. 

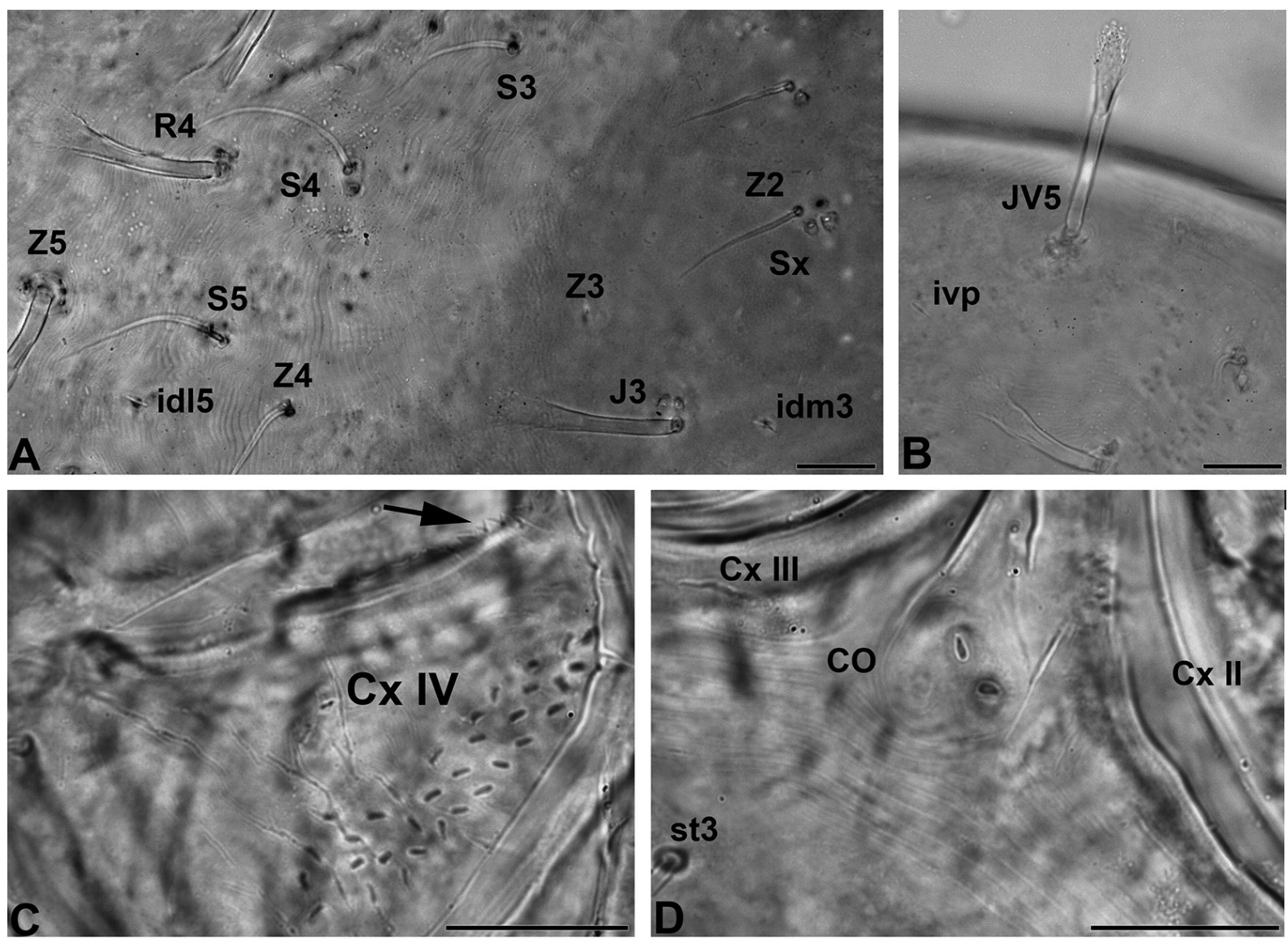

Fig. 4. Uroseius subterraneus sp.n. female. A - detail of dorsal idiosoma showing heteromorphic setae on dorsal shield and membranous marginal cuticle; $\mathrm{B}$ - detail of idiosoma showing ventral setae; $\mathrm{C}$ - coxa IV (CxIV) showing glandular fields, arrow points to the serrate surface; D-region between coxae (Cx) II and III showing the cuticular organ on a rounded platelet (CO); setae and pores named according to Moraza (2019). Scale bars $=50$.

Venter (Fig. 5A). Sternigenital, endopodals and anal regions distinctly sclerotized, other areas with 1 thinner cuticle despite being darker than membranous dorsal cuticle. Exopodal II-IV faintly paneled. 5 pairs of sternal setae thin and smooth 25-34 (29), with st 1-st3 in front of genital opening, st4 flanking opening and st 5 posterior, associated to glandular opening and leveling with lyrifissures iv5. Genital opening at level of anterior margin of coxae IV, 72 long, 62 wide, with 2 valves, anterior valve almost circular and posterior valve crescentshaped. Genital valves nude. Peritremes similar to those of female. Stigma situated between coxae II and III.

Anal shield sclerotized, cone-shaped, 80 long, 111 wide; 2 pairs of minute smooth adanal setae 12, pair of gv3 lateral on anal shield.

Opisthogastric region. Similar to that of female, bearing 4 pairs of smooth and needle-like setae (JV1-JV2, ZV1-ZV2) 32-47(38) and 4 pairs of distally pilose setae (JV3-JV5, ZV4) 65-74 (70) associated with gland pores.
Gnathosoma. Gnathotectum as in female. Chelicerae 50 long excluding basal segment; movable cheliceral digit 38 long, morphology similar to female. Hypostomal setae smooth, length: $h 3$ (78) > $h 1(63)>h 4(16)>h 2$ (8). Corniculi stout. Palps as in females, 167 long.

Legs. Leg chaetotaxy as described for female. Leg lengths (excluding pretarsi): I (590), II (536), III (557), IV (576). Leg I tarsus (170) about 2.6 times longer than tibia (63). Setae $a v-1$ on femur II modified into spur, $a v-1$ on genu II and tibia II modified into thumb-like knob and in acute spine on tarsus II (Fig. 3E).

Juveniles: unknown.

Type material. Female holotype (UFMG AC 173943) in an iron ore cave (CS-09) at Serra do Sapo, Municipality of Conceição do Mato Dentro, State of Minas Gerais, Brazil (18 $\left.56^{\prime} 11^{\prime \prime} \mathrm{S}, 43^{\circ} 24^{\prime} 45^{\prime \prime} \mathrm{W}\right)$, 15-22 Jan. 2014, coll. Carste Ciência e Meio Ambiente. Female paratype (UFMG AC 173944), collection data same as for holotype. Female paratype (UFMG AC 210144) in a quartzite cave (S1MLT 


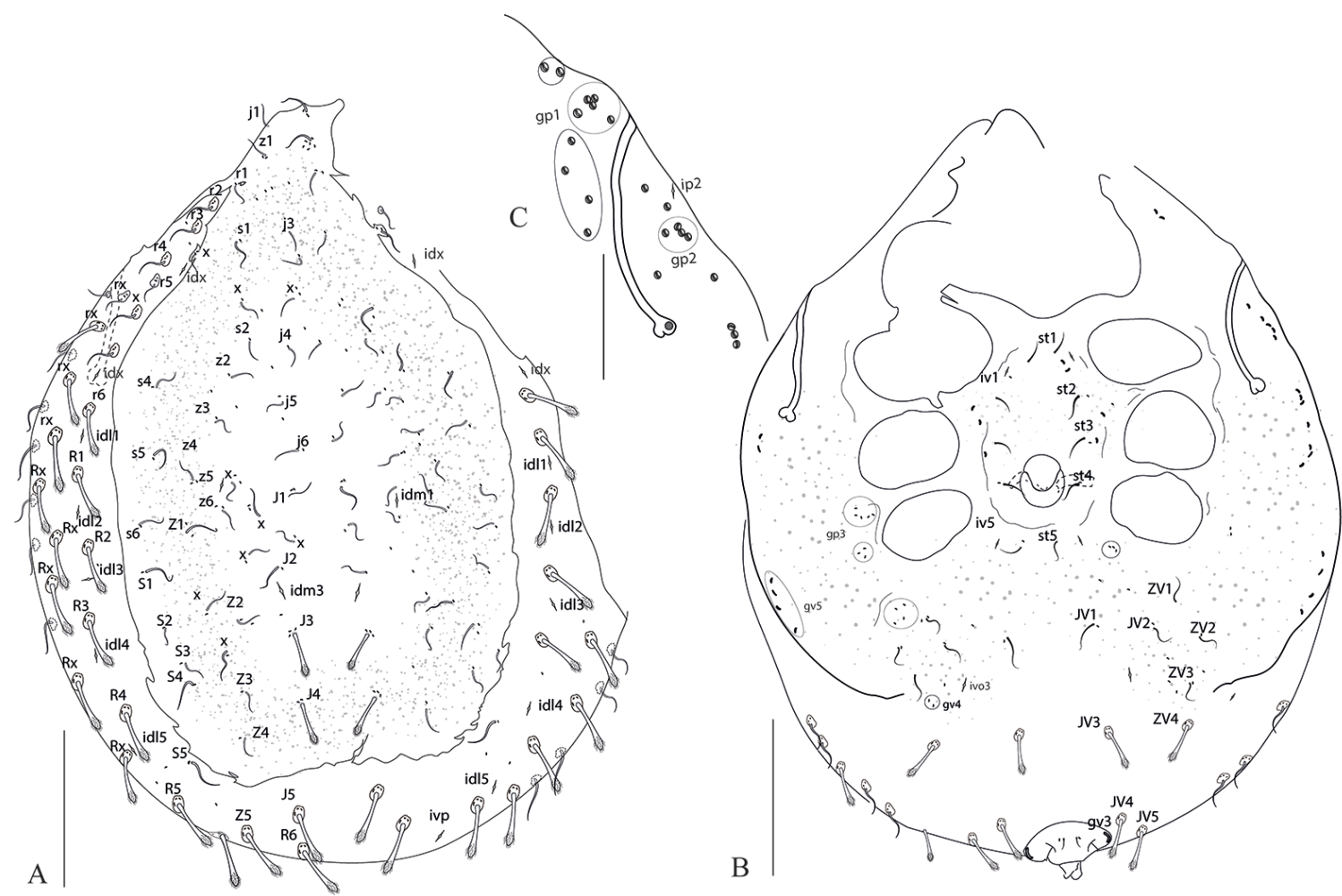

Fig. 5. Uroseius subterraneus sp.n. male. A — idiosoma ventral view; B-idiosoma dorsal view; C-detail of peritremal area and stigma; setae and pores named according to Moraza (2019). Scale bars: A, B=200; $=100$.

009), Municipality of Santa Bárbara do Monte Verde, Mantiqueira Ridge, State of Minas Gerais, Brazil (21 $\left.{ }^{\circ} 56^{\prime} 55^{\prime \prime} \mathrm{S}, 43^{\circ} 44^{\prime} 09^{\prime \prime} \mathrm{W}\right), 24-27$ Jun. 2020, coll. Eq. Spelayon. Male paratype (UFMG AC 172895) in an iron ore cave (SPT-0585), Municipality of Conceição do Mato Dentro, State of Minas Gerais, Brazil (19 $\left.10^{\prime} 30^{\prime \prime} \mathrm{S}, 43^{\circ} 15^{\prime} 55^{\prime \prime} \mathrm{W}\right), 12-14$ Jun. 2017, coll. Carste Ciência e Meio Ambiente.

Type depositories: type material deposited at "Centro de Coleções Taxonômicas da UFMG (CCT-UFMG)".

Etymology. The species name refers to the fact that the specimens were collected inside of caves.

Remarks. The genus Uroseius, including $U$. subterraneus sp.n., comprises 20 species. Four of them are represented by adults: U. loksai Kontschán, 2012; U. rotundus Hiramatsu, 1981; U. subterraneus sp.n.; and U. willmanni Hirschmann and Zirngiebl-Nicol, 1969). Six of the species are represented by both adults and deutonymphs: U. acuminatus (Koch 1847); U. degeneratus Oudemans, 1913; U. foetidus Moraza and Pérez-Martínez, 2019; U. hunzikeri Schweizer, 1922; U. sorrentinus Lombardini, 1952; and U. tuberosus Hirschmann and Hiramatsu, 1971. The remaining ten species are represented by deutonymphs only. Two species$U$. subterraneus sp.n. and U. sorrentinus - had their males described (Moraza 2019, present study).
Among the nine species with described females, three are neotropical, found in Ecuador: U. tuberosus Hirschmann and Hiramatsu, 1977; U. loksai Kontschán, 2012; and U. rotundus Hiramatsu, 1981. Uroseius subterraneus sp.n. differs from the above three species in having dual setal morphology, with some setae smooth, short and needle-shaped and others long, stout, barbed clubshaped (Kontschán 2012). In U. tuberosus, all setae are pilose and long, while in $U$. loksai and $U$. rotundus all setae are smooth and short. Additionally, U. tuberosus has a caudal idiosomal protuberance, which is absent in all other Uroseius (Kontschán 2012).

The heterogeneous morphology of setae observed in U. subterraneus sp.n. was, until now, thought to be a feature restricted to the Paleartic species of the Uroseius genus (Karg 1989, Moraza and Pérez-Martínez 2019). The distribution of setae with different morphologies relative to the sclerotization varies among Paleartic species, however, and the only species with a similar distribution of setal morphologies on dorsum is the recently described U. foetidus. Uroseius foetidus and U. subterraneus share two pairs of stout and barbed club-shaped setae on dorsal shield (J3-J4) and both smooth, short needle-like and stout barbed clubshaped setae on laterodorsal idiosoma. 
Uroseius subterraneus sp.n. differs from $U$. foetidus in the shape and size of the ventral and marginal setae. Uroseius subterraneus sp.n. has a marginal, ventral bending row with 10-13 pairs of smooth needle-like setae 38-66 (this range includes females and one male) and setae $J V 1-J V 2, Z V 1-$ ZV2 32-47 long (this range includes females and one male), while all of the above setae are very short or vestigial in $U$. foetidus. Another distinctive feature is the relative size of hypostomal setae: in $U$. foetidus, hypostomal seta $h 2$ is as long as or slightly longer than the distance to the base of $h 1$, and the palpcoxal seta $h 4$ is clearly the shortest; in $U$. subterraneus sp.n., $h 2$ is the shortest setae, even shorter than $h 4$.

This is the second species of Uroseius from which a male is described. It confirms the observations of $U$. sorrentinus (Lombardini, 1952), in which males and females differ in leg II: with setae $a v$ modified as spurs (which are pointed on femora and assume the shape of a blunt knob on genu and tibia) and tarsus II with enlarged, spine-like seta in males. The males and females also differ in bearing some pairs of setae on dorsal shield in males whereas in female they are on striated dorsal cuticle, namely J5, Z4, Z5 in U. sorrentinus and $S 3-S 4$ and Z4 in U. subterraneus sp.n. Males of $U$. subterraneus sp.n. differ from those of $U$. sorrentinus in having nude genital valves (vs. U. sorrentinus males having a pair of eugenital setae on anterior valve).

\section{Family Oplitidae Johnston, 1968 Genus Oplitis Berlese, 1884}

Diagnosis. The concept of Oplitis used here is based on that of Lopes, Oliveira, Delabie and Klompen (2015).

\section{Oplitis apicalis Lopes, Oliveira, Delabie and Klompen, 2015}

Adult diagnosis. Idiosoma longer than wide, with dorsal shield relatively smooth, with punctuated appearance at high magnifications. Dorsal setae scimitar-shaped. Central dorsal and lateral dorsal regions distinct, merging anteriorly. Marginal shield fused anteriorly with dorsal shield, its setae simple acuminate. Ventral regions of idiosoma similarly smooth, pedofossae present, with pedofossae IV with a pointed tip, gradually narrowing, but with a distinct constriction before the tip. Presence of 3-4 ventral setae. Operculum rounded anteriorly, largely straight posteriorly. Perigenital structure surrounding the genital shield.
Anterior and posterior margins of perigenital structure crenulate, with 5 crenulations on anterior and 5-7 crenulations on posterior margins. Anal shield separated from ventral shield by a pre-anal line. Posterior paranal setae distinctly smaller than the anterior paranal setae, corresponding to $0.5-0.33$ of their length. Anterior branch of the peritreme convolute, mushroom-shaped. Gnathotectum with 3 pointed projections.

Description. Measurement ranges are compared to the original description (in parentheses).

Dorsum. Marginal shield width 20-25 (17-23). Dorsal shield setae 23-29 (17-38) long, slender, scimitar-shaped. Marginal shield setae short, 13-15 (11-16), simple, acuminate.

Venter. Operculum situated between coxae II-IV, 153-156 (149-168) long, 105-107 (104$115)$ wide. Perigenital shield elliptical with 5 (5) crenulations on anterior and $6(5-7)$ crenulations (holotype 6) on posterior margins. Perigenital shield longer than wide, 230-232 (223-250) long and 118-120 (114-129) wide. Perigenital area with short setae, length 4-5 (3-6). Pre-anal line present. Setae on ventral and anal shields slender, scimitarshaped 24-26 (23-30) in length. Peritremes triconvolute, with a tight mushroom-shaped loop in the middle of the anterior branch.

Gnathosoma. Chelicerae with a distinct "nodus", fixed digit 45 (49-57), movable digit 32 (37-40). Fixed digit with 2 teeth, movable digit with one tooth. Palpal apotele distinctly 3-tined. Trochanteral setae $\mathrm{v} 1$ and long tarsal setae slightly barbed, other setae smooth; genual setae short, thick, spinelike, other setae thin, setiform. Setal formula: 2-4-5-12-14. Gnathotectum tripartite, lateral branches almost as long as median; margins of entire gnathotectum with large, somewhat irregular denticles. Labrum (la) singular, covered throughout with similar-sized, small fimbriae. Lateral lips featherlike, bushy. Hypostomal setae $h 1$ smooth, $h 2$ with a few small barbs, $h 3$ with coarse barbs in median section, and subcapitular setae ( $s c$ ) with small, dense barbs along entire length $(h 3>s c>h 1=h 2)$. Corniculi horn-like. Tritosternum vase-shaped, with smooth surface; laciniae three-branched, the middle branch bifurcate apically.

Legs. Coxae I-IV with dense small punctuations. Length of leg I 240-253 (203-283), leg II-224-238 (232-270), leg III-226-232 (212253, 236), leg IV-248 (228-281, 252). Leg setation I-IV: coxae: 2-2-2-1; trochanters: 4-3-3-3 (trochanters I with both dorsal setae setiform, smooth, $a l$ and $p l$ both arborescent near tip); 
femora: 1 2/1 2/1 1, 1 2/1 2/1 1, 1 2/1 1/1 0, $12 / 1$ 2/1 0 ( $p d 2$ and $p l$ absent on femora III, $p l$ also absent on femora IV); genu: $12 / 12 / 11,12 / 12 / 1$ 1, $12 / 12 / 01,12 / 12 / 0$ 0; tibiae: all 1 1/1 2/1 1; tarsi II-IV: all 3 3/2 1/1 3/2 3(setae ad1 and pd1 thin, other dorsal setae spine-like). Femoral setae $p v$ II-IV wide 2.0 (3.5) and long. Femora I-IV with ventral lamellae. All pretarsi with claws.

Examined material. All mites were obtained from iron ore caves at Conceição do Mato Dentro, State of Minas Gerais, Brazil and collected by the staff of the company Carste Ciencia e Meio Ambiente. Two females (UFMG AC 174526-7), cave ASS-10 at Serra do Sapo, $18^{\circ} 55^{\prime} 37^{\prime \prime} \mathrm{S}, 43^{\circ} 24^{\prime} 55^{\prime \prime} \mathrm{W}$, 27 Feb.-9 Mar. 2012; Female (UFMG AC 170361), cave CSS-0097, 18 $56^{\prime} 42^{\prime \prime} \mathrm{S}, 43^{\circ} 24^{\prime} 20^{\prime \prime} \mathrm{W}, 31$ May-12 Jun. 2016; Female (UFMG AC 171830),

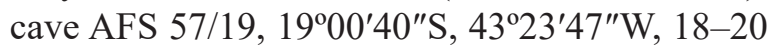
Apr. 2016; Female (UFMG AC 172611), cave MSS 78/19, 1900'40"S, 43ํ3'47"W, 16 Dec. 2015; Female (UFMG AC 172835), 1900'28"S, $43^{\circ} 23^{\prime} 48^{\prime \prime} \mathrm{W}, 10$ Sep. 2015.

Comparative material examined: 2 female paratypes, collected from Neoponera verenae (Formicidae) at Municipality of Gandu, State of Bahia, Brazil (13044'31"S, 39³9'50"W), 17 Jun. 2014, coll. Juliana M. S. Lopes. Both deposited at Escola Superior de Agricultura "Luiz de Queiroz".

Remarks. No significant difference could be found when comparing the individuals reported here to the original description of Oplitis apicalis. It is noteworthy that both species, $O$. apicalis and $U$. subterraneus, have no special morphological features (troglomorphisms) that may be related to subterraneous environments. Indeed, the original description of $O$. apicalis was based on epigenous material associated with ants. Since the mites described herein were sorted from material collected in caves, it is possible that our specimens detached from the ants before being studied.

Another species of Uroseius, U. sorrentinus, was collected from caves in Spain and Italy from different depths inside the caves. Similar to the species reported herein, it also has no morphological features that suggest troglodytism (Moraza 2019). Hence, we regard both species as troglophile or trogloxenes, i.e. non-obligate cave inhabiting mites (Sket 2008).

\section{ACKNOWLEDGMENTS}

The authors thank the company Carste Ciência e Meio Ambiente for handling the specimens used in this description. The work was supported by the mining company AngloAmerican. Special thanks to Lorena Oliveira Pires (Environmental Analyst) and Ligia M.S. Moreira for making the material available.

The writing of this manuscript was possible due to the support offered to ARP as a postdoc at Tyumen State University, Russia, and to PHSC by ADESITA (contract No. 04/2016-Agência de Desenvolvimento Econômico e Social de Itabirito). Special thanks go to Dr. Gilberto José de Moraes (Universidade de São Paulo), who kindly hosted PHSC at Escola Superior de Agricultura "Luiz de Queiroz".

We also thank Dr. Hans Klompen (Ohio State University) for useful tips on specimen identification, and Dr. Leopoldo Ferreira de Oliveira Bernardi for kindly sharing one of his specimens and for his remarkable enthusiasm regarding cave dwelling mites. We are also grateful to Dr. María L. Moraza (Universidad de Navarra) for her comments on an earlier draft of this manuscript.

\section{REFERENCES}

Ainscough, B.D. 1979. Recent advances in the classification of the Uropodina. In: J.G. Rodriguez (Ed.). Recent Advances in Acarology. Vol II. Academic Press, New York, pp. 451-454.

Babaeian, E., Saboori, A., Gwiazdowicz, D.J. and Etemad, V. 2016. Redescription of two species of Oplitis Berlese (Acari, Mesostigmata, Oplitidae) from Iran. ZooKeys, 610: 13-22. DOI: 10.3897/ zookeys.610.9965

Beaulieu, F., Dowling, A.P.G., Klompen, H., de Moraes, G.J. and Walter, D.E. 2011. Superorder Parasitiformes Reuter, 1909. Zootaxa, 3148(1): 123-128. DOI: 10.11646/zootaxa.3148.1.23

Berlese, A. 1884. Acari, Myriopoda et Scorpiones hucusque in Italia reperta, 11, 13 text pp. + pl. 1-10. [Reprinted by Junk, The Hague, 1979]

Berlese, A. 1888. Acari, Myriopoda et Scorpiones hucusque in Italia reperta, 49, 15 text pp. + pl. 1-10. [Reprinted by Junk, The Hague, 1979]

Bernardi, L.F.O., Zacarias, M.S, Silva, M.S. and Ferreira, R.L. 2009. Ácaros cavernícolas do Brasil: uma observação preliminar sobre a ocorrência e distribuição das famílias. Mundos Subterráneos, 20: 5-13.

Green, J. and Macquitty, M. 1987. Halacarid Mites. Linnean Society of London/Estuarine and BrackishWater Sciences Association and E. J. Brill/W. Backhuys, London, 178 pp.

Halliday, R.B. 2015. Catalogue of genera and their type species in the mite Suborder Uropodina (Acari: Mesostigmata). Zootaxa, 3972(2): 101-147. DOI: 10.11646/zootaxa.3972.2.1 
Hirschmann, W. 1991. Gangsystematik der Parasitiformes. Teil 528. Die Gangattung Oplitis Berlese, 1884: Artengruppen, Bestimmungstabellen, Diagnosen (Trachyuropodini, Oplitinae). Acarologie, Schriftenreihe für vergleichende Milbenkunde, 38: 1-106.

Hirschmann, W. and Zirngiebl-Nicol, I. 1961. Gangsystematik der Parasitiformes, Teil 4: Die Gattung Trichouropoda Berlese 1916, Cheliceren und System der Uropodiden. Acarologie, Schriften-reihe für Vergleichende Milbenkunde, 4: 1-41 + pl. 1-15.

Hirschmann, W. and Zirngiebl-Nicol, I. 1964. Gangsystematik der Parasitiformes. Teil 7. Uropodiden. Das Gangsystem der Familie Uropodidae (Berlese 1892) Hirschmann und Zirngiebl-Nicol nov. comb. Bestimmungstabellen, Kurzdiagnosen, Operculum-Bestimmungstabellen. Acarologie. Schriftenreihe für Vergleichende Milbenkunde, 6: 1-22.

Karg, W. 1989. Uropodina Kramer, Schildkriitenmilben: Acari (Acarina), Milben, Unterordnung Parasitiformes (Anactinochaeta). Tierwelt Deutsch. 67. Gustav Fischer, Jena, 203 pp.

Kontschán, J. 2012. Notes on the distribution and taxonomy of the Ecuadorian Uropodina mites (Acari: Mesostigmata). Opuscula Zoologica Budapest, 43(1): 27-42.

Lindquist, E.E., Krantz, G.W. and Walter, D.E. 2009. Order Mesostigmata. In: G. W. Krantz and D.E. Walter (Eds.). A Manual of Acarology. $3^{\text {rd }}$ ed. Texas Tech University Press, Lubbock, pp. 124-232.

Lopes, J.M.S., Oliveira, A.R., Delabie, J.H.C. and Klompen, H. 2015. A new species of myrmecophile mite of the genus Oplitis (Acari: Mesostigmata: Oplitidae) from Brazil. International Journal of Acarology, 41 (8): 676-680. DOI: 10.1080/0164 7954.2015.1096960

Moraza, M.L. 2019. New data on the genus Uroseius Berlese (Acari: Mesostigmata: Uropodina: Trachytidae) with a redescription of $U$. sorrentinus (Lombardini, 1952). Zootaxa, 4717(1): 7-29. DOI: 10.11646/zootaxa.4717.1.4

Moraza, M.L. and Pérez-Martínez, S. 2019. The genus Uroseius Berlese (Acari: Mesostigmata: Uropodina: Trachytidae) in the Iberian Peninsula with description of a new species associated with animal remains. Systematic and Applied Acarology, 24(5): 929-944. DOI: 10.11158/saa.24.5.14

Rodrigueiro, T. S.C. and Prado, A.P. 2004. Macrocheles muscaedomesticae (Acari, Macrochelidae) and a species of Uroseius (Acari, Polyaspididae) phoretic on Musca domestica (Diptera, Muscidae): effects on dispersal and colonization of poultry manure. Iheringia. Série Zoologia, 94(2): 181-185. DOI: $10.1590 / \mathrm{s} 0073-47212004000200011$

Sket, B. 2008. Can we agree on an ecological classification of subterranean animals? Journal of Natural History, 42(21-22): 1549-1563. DOI: 10.1080/ 00222930801995762

Walter, D.E. and Krantz, G. W. 2009. Collection, rearing and preparing specimens. In: G. W. Krantz and D.E. Walter (Eds.). A Manual of Acarology. $3^{\text {rd }}$ ed. Texas Tech University Press, Lubbock, pp. 83-96. 